\title{
Attitudes and risks concerning the management of the career of young engineers
}

\author{
Traian FLESER ${ }^{1, a^{*}, \text { Ranko SZUHANEK }}{ }^{2, b}$, Emilia BINCHICIU ${ }^{3, c^{*}}$ \\ and Camelia SZUHANEK ${ }^{4, d}$ \\ ${ }^{1}$ „Politehnica” University of Timisoara, Victoriei Str., 2, Romania, \\ 4 "Victor Babes" University of Timisoara, Eftimie Murgu Str., 2, Romania \\ $\mathrm{a}^{*}$ trfleser@yahoo.com, ${ }^{\mathrm{c}^{*}}$ emilia.binchiciu@gmail.com
}

Keywords: student, young engineer, labour field, abilities, professional selection.

\begin{abstract}
The quality of an academic educational system can be seen in the educational performances of students, but most of all in the way it ensures a professional career that is adequate to their studies. One can think of concepts as: education for a career, development, planning and management of the career, methods, instruments, strategies and techniques in the management of potential and implied risks. The characteristics of an education for a career in university training are presented in comparison to stages of one's professional activity. The paper introduces the strategies for career management and techniques of making successful planning.
\end{abstract}

\section{Introduction}

Education represents a major element for professional development and for a certain moral standard. These could be the reasons that make academic study so important; it should be placed on the foremost position. The young people are studying nowadays at engineering faculties $(>1 / 4$ total amount of Romanian students), according to the National Statistics Institute (tab. 1)[1, 2].

Table 1 Distribution of students in academic year 2011-2012, engineering fields

\begin{tabular}{|c|c|c|c|c|c|c|c|c|}
\hline Field & $\begin{array}{c}\text { Econo- } \\
\text { mic }\end{array}$ & $\begin{array}{c}\text { Syst. \& } \\
\text { Comp. }\end{array}$ & Civil & $\begin{array}{c}\text { Mecha- } \\
\text { nical }\end{array}$ & Food & $\begin{array}{c}\text { Elec- } \\
\text { tronic }\end{array}$ & $\begin{array}{c}\text { Indus- } \\
\text { trial }\end{array}$ & $\begin{array}{c}\text { Environ- } \\
\text { mental }\end{array}$ \\
\hline Students & 20157 & 14419 & 11345 & 9982 & 9145 & 8452 & 8595 & 8430 \\
\hline Field & Electrical & Energy & Naval & Chemical & $\begin{array}{c}\text { Transport- } \\
\text { ation }\end{array}$ & $\begin{array}{c}\text { Mate- } \\
\text { rials }\end{array}$ & Total \\
\hline Students & 8452 & 3370 & 2835 & 2826 & 2281 & 1942 & 138462 \\
\hline
\end{tabular}

Around 50.000 engineers wait for the graduation exams yearly, this is the number expected to fill the needs of the labour field. In EU countries there are almost 75 million young people involved in professional activities. The employers who hire young engineers claim that from a quality point of view they are quite well prepared, theoretically, although they have significant gaps on practical aspects.

The courses' curriculum hasn't caught up with the speed of changes in the engineering field. EU program for research and innovation - Horizon 2020 for sup industry since 2014, areas of information and communication technologies, nanotechnologies, advanced manufacturing systems, robotics, biotechnology and space research.

Companies have to come up with specific training programs, developed on their own or in partnership with universities, in order to ease the assimilation of young engineers in the labour field.

Practice focuses on master programs or training, with precise purposes. In Romania and in other countries successful graduation does not guarantee direct access to the labour field. There are few domains, like employers, that are constantly assimilating or offering programs to integrate young people. Professional experience is achieved in time by cumulating knowledge in various fields, 
finding the appropriate job depends a lot on the proved and acknowledged abilities in a certain domain. Top choices of young people for employment in 2013 (IT and engineering), tab. 2.

Table 2 Top choices of young people for employment in 2013 (IT and engineering)

\begin{tabular}{|l|l|l|l|l|l|l|l|l|l|l|}
\hline Company & $\begin{array}{l}\text { Conti- } \\
\text { nental }\end{array}$ & $\begin{array}{l}\text { Micro- } \\
\text { soft }\end{array}$ & $\begin{array}{l}\text { Dacia } \\
\text { (Renault) }\end{array}$ & $\begin{array}{l}\text { Goo- } \\
\text { gle }\end{array}$ & $\begin{array}{l}\text { Volks } \\
\text { wagen }\end{array}$ & $\begin{array}{l}\text { BMW } \\
\text { Group }\end{array}$ & $\begin{array}{l}\text { Hydro- } \\
\text { power }\end{array}$ & $\begin{array}{l}\text { Sie- } \\
\text { mens }\end{array}$ & $\begin{array}{l}\text { O- } \\
\text { range }\end{array}$ & IBM \\
\hline Share[\%] & 11,1 & 7,8 & 7,5 & 7,5 & 6,2 & 5,8 & 5,6 & 5,3 & 5,2 & 5,0 \\
\hline
\end{tabular}

Thus, connecting with the labour field, the current stage can be achieved by a part-time job, by getting involved in an internship program or by volunteering. A well-chosen internship can represent, for students, the chance to experiment work in a company and gaining a certain involvement in a team, a fact that doesn't limit or prevent continuing with one's studies.

The purpose of the paper is to make an analysis and presentation of young engineer's attitude, of the risks appearing in the evolution and professional development of their career, together with the effects of secondary causes.

\section{Factors that influence the integration of young people in the labour field}

The EU strategy regarding the integration of young people in productive activities stresses the necessity "for a better advertisement" and education, about taking risks at small ages, but also points out the moment when they are really part of a working team. This is possible due to the development of the culture of risk prevention as the main element for maintenance and improvement of work and life conditions.

In actuals standards certain activities are a source for emotional, cognitive behavioural and physiological reactions. The lack of correlation between oneself and ones work, the conflicts between our roles during work and outside it, the lack of a reasonable degree of control over our own work and life has its own stress level.

In the following we analyse situations which should bring an optimistic attitude among young people in order to find the intellectual and physical possibilities:

a. Regarding the professional risks to which young people can be exposed, the New UE Strategy on health and work safety domain imposes priorities, stresses new risks that are characteristic for the current technical and economic stage of "information society", including psycho-social risks, mainly psychological stress.

Young people are a group with an increased risk. The situation is caused by: health and social issues of teenagers and young people that tend to be ignored, transitioning towards adulthood, getting to work - the official occupation (or a prolonged unemployment) and leaving the family determine quick social changes and conflicting social values which are often ambiguous.

Statistics emphasize that young people are more vulnerable to professional risks because of: lack of experience and knowledge about the task and the work environment; the lack of awareness regarding professional risk, also lack of information / training in the WHS field; the lack of awareness of employers regarding personal rights and responsibilities; sometimes, lack of full physical and mental maturity.

In such situations one can meet with: the tendency to undervalue the risk of injuries or professional diseases; sometimes, adopting a risky attitude and behaviour in a particular activity.

One emphasizes the factors that create a balance regarding professional activities (fig.1). One can make a difference between groups of factors which determine or increase the vulnerability of young people to psycho-social risks (tab. 3).

b. Resources of adaptation. Young people that get employed can use resources / elements which influence their adaptation to work in a positive way, both technically and organizationally or psycho- social. 


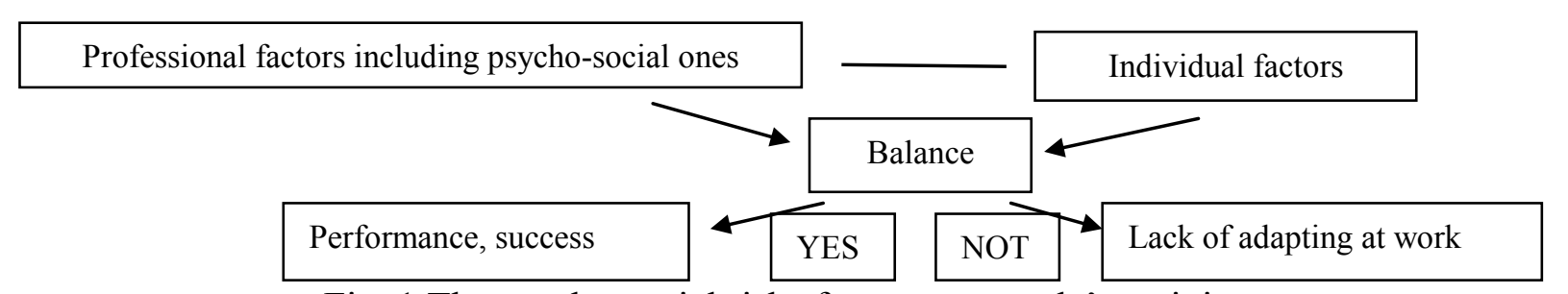

Fig. 1 The psycho-social risks for young people's activity

Table 3 Factors which determine/increase the vulnerability of young people to psycho-social risks

\begin{tabular}{|c|c|c|}
\hline Types of stress elements & $\begin{array}{l}\text { Factors depending on the } \\
\text { young }\end{array}$ & $\begin{array}{l}\text { Factors depending on the } \\
\text { employers }\end{array}$ \\
\hline $\begin{array}{l}\text { A. Stress caused by proper } \\
\text { activity: } \\
\text { - repetitive activity or few } \\
\text { tasks to accomplish, many } \\
\text { tasks to accomplish in too } \\
\text { short a time, } \\
\text { - confusion referring to } \\
\text { responsibilities and team } \\
\text { relationships, } \\
\text {-confusion about priorities, } \\
\text { timing and quality levels. } \\
\text { B. Stress caused by the work } \\
\text { relationships: } \\
\text { - few relationships among } \\
\text { colleagues, } \\
\text { - intimidation or harassment, } \\
\text {-lack of communication } \\
\text { between the manager, the } \\
\text { coordinator and young } \\
\text { people, } \\
\text { - negative organizational } \\
\text { culture, based on blaming } \\
\text { and identifying the guilty } \\
\text { persons }\end{array}$ & $\begin{array}{l}\text {-vulnerability to intimidation } \\
\text { from part of the colleagues } \\
\text { and coordinator based on } \\
\text { inferior status or a recent } \\
\text { employment; } \\
\text {-the "estrangement" of the } \\
\text { manager from young people, } \\
\text { difficulties in organization } \\
\text { and control of one's own } \\
\text { activity. }\end{array}$ & $\begin{array}{l}\text { - accomplishing tasks that do } \\
\text { not match the skills; } \\
\text { - lack of information, } \\
\text { instruction and training skills; } \\
\text {-lack of awareness that young } \\
\text { people have reduces } \\
\text { experience, knowledge and } \\
\text { training in comparison to given } \\
\text { tasks, namely the WHS } \\
\text { aspects. } \\
\text {-inadequate supervision of } \\
\text { young people at the work } \\
\text { place; }\end{array}$ \\
\hline
\end{tabular}

Socially: a good theoretical training, especially the wish to improve oneself as a specialist, to develop abilities specific for tasks they have to understand; under circumstances of support and counselling, some stress factors can become stimulating factors for the development of a larger vision regarding work and organization; opening to information about professional risks, safety and work health, being ready to act in order to protect themselves when they know about potential dangers.

The development of educational and training policies in the sense that UE education and training systems should become a reference point, worldwide, in the quality domain in 2010 - 2020. The Bologna Process document, signed by Romania too, to reform the university educational system, being at the beginning of one's professional activity, young people can: be exposed more to risks than their older colleagues, cause of their own lack of experience, of training and awareness of risks; have the right to a safe and healthy work environment as well as the right to ask questions and to get answers, to underline the aspects that seem unsafe to them; have the need of good counselling, information, safer and healthier working places. 


\section{Career education}

Life evolution depends on the evolution of permanent and a long term education. Career education includes obtaining the abilities that make the candidate capable to have a professional career in a satisfactory manner, to apply at great opportunities, to be able to self-evaluate objectively. Young engineers must see "where are they now and where do they want to be in the future"[3].

The concept / career education activity includes topics that are not apparently linked to working in a profession; still it has a direct influence on it, such as: family life, spending free time, educating children, family savings, value and quality of life, the way to deal with unexpected situations in life.

A special importance have the approach in management concepts- in order to define and achieve targets in the development and career planning stages; the responsibilities of one's educational trainer, of the employee and of the counselling manager for career development. Career counselling partially represents one of the career management elements. The counselling process must be properly oriented, according to the stage, the type and the position of the person, also the action plan, made after the counselling session, has to be part of the career planning file.

Through counselling programs the young must be prepared to adapt their way of thinking to new requirements of ever changing labour field and society. Thus, trainers and their counsellors need to offer them. from the very beginning, the necessary knowledge to plan a future career. When starting a university study cycle, one supposes that young people have already been advised vocationally in order to make a successful option. In university they can check the value of their previous professional options and improve the abilities needed for the chosen career.

In every university there are counselling and work employment centres for students that ensure the link between university and economic, administrative, social and cultural environment. These centres have training problems support as well as work field integration support purposes. Counsellors and analysts of centres offer students training and counselling service for career management.

Career planning is a process through which the candidates evaluate their weak points, their strong ones, the development opportunities inside an organization, their set of objectives and plans by which to orient their own career in the chosen direction.

\section{Career management strategies}

In what students are concerned, counselling focuses mainly on practicing management strategies and making a career plan. Career strategies suppose anticipating the important problems and long term planning by underlining:

- $\quad$ self-knowledge: objectives, abilities, interests, individual potential, strong/weak points;

- knowledge of professional environment: company profiles, work conditions, number of employees, opportunities, dangers, economic problems, rival companies.

- professional self-evaluation: stressing self-abilities, capacities and competences, ability to start and fulfil projects.

- adaptability, flexibility, spirit of competition: ensuring a permanent correspondence between the personal abilities which are possibly used in the labour field, to be open to change.

- specialization combined with culture: development and evaluation in a professional domain, parallel to up-to-date information.

- self-recognition: the acknowledgment of self-achievement and results.

- preparing a secondary plan: for immediate action situations.

- $\quad$ keeping a good health condition: physical, psychological, material, spiritual.

Due to these strategies young people can be supervised in the process of developing an initial career plan. They must be encouraged to explore application paths, avoiding accepting the first job in emotional and less reasonable circumstances. One looks for a displacement of mentality, according to which students or young graduates can accept any job because of their lack of practical experience. A serious career planning can ensure a promising approach from the very beginning. 
A successful career planning starts with information, documenting and investigating the obvious and less obvious requirements that are asked by getting employed in a position adequate to ones goals, studies and individual availability. An efficient self-analysis method is the SWOT analysis. It is a necessary and much used instrument in strategic planning processes which can be applied in career planning. One takes into account internal and external reality, evaluating strong and weak points in an internal environment, including opportunities and threats of the external environment. The candidate, a student or a graduate, makes objectively his own SWOT analysis, stressing the strong and weak aspects of his personality, the main opportunities and fears in the chosen domain. The opportunities underline the positive external conditions that are unexpected, but that can be used for one's own advantage. The weak points are not favourable, they are negative aspects which can be diminished and improved. Fears (threats) are negative external conditions that are unexpected, but results can be predicted and avoided. Interpreting the results can start an objective career plan, well based and linked to other requirements:

- self-assessment,

- defining purposes and objectives,

- knowing career theories which orient the vision of manager at ones future workplace,

- making a predictive plan on a determined period,

- making a priority list in one's career,

- finding a mentor,

-getting flexible arrangements at one's job: part-time, job-sharing, flex-time, telecommuting,

- understanding one's personal motivation,

- establishing the geographical area,

- clarifying the position and the chosen function,

- mastering the presentation and image methods as well as their stressing before the employer.

If student or graduate makes their career plan using these strategies, it is possible they will have a successful career, because he will be assisted every step of the way. Linked to this objective, the European Pact for Young People adopted in spring 2005 at the EU summit sets as a strategy the element of creating qualitative work places. Candidates can get familiar with a mentality specific for safety and health, with risk prevention through school and university curricula. Teaching these values to young people at an early age will contribute to promote a prevention culture linked to a optimistic approach about work place tasks. Young engineer who graduated a technical faculty have the dream of a well-fare life and they want to make a solid basis for the future. This is largely conditioned by jobs that:

- correspond to purpose, interests and professional expectations,

- offer the possibility to use knowledge and abilities,

- allow the person to set his own priorities in fulfilling the work tasks,

- establish professional and realistic purposes and create the possibility of professional development,

- offer support, work safety and counselling.

Every engineer graduate, not only though, looking for a job, must also be informed on essential aspects for a professional achievement:

- knowledge of the current labour legislation,

- the rights and obligations of employee according to the individual work contract,

- the relation between one's own abilities and the requirements of the employer /the standards of the position,

A successful career management implies:

- knowledge about career planning,

- finding the adequate job,

- capacity to adapt to new tasks or new jobs,

- learning abilities. 
These constitute a challenge for those involved in the process of evolving towards engineering professions. It is psychologically a critical period, coinciding with passing from an academic technical learning stage to a professional life. The development of abilities as preparing a career management focuses on offering qualitative jobs and preventing psychological problems linked to the absence of a job or an unsatisfying work place. The professional project represents a systematic way of self-involving and professional orientation of the candidate in order to find the most adequate professional road for career accomplishment. One uses:

- assessment of self-competence, knowledge and personal qualities with the help of counsellors specialized in work psychology,

- finding information about the particular social-economic environment,

- possible professional trajectories and their comparison to the social-economic reality,

- elaborating, analysing and using a valid professional project.

The successful professional project is closely linked to socio-professional integration by two components:

- the assimilation of the candidate by the community and adapting to its requirements,

- getting information about the community and initiation on the complexity of the tasks that depend on:

-work adaptation: knowing particular obligations, -assimilation: understanding the necessity of adopting proper attitudes, -identification with work: adopting a behavioural model.

\section{Career evolution and risks}

Career can be considered a purpose or a wish fulfilled through education. Great importance is given to the methods by which one should ensure a career development: career oriented counselling, initial and continuous professional formation, promotion and career education. Given the current opinions, career follows a succession of professions, jobs, positions, functions assumed during one's active life which presupposes more or less favourable occupational fluctuations from one age to the other[4, 5].

In what Romanians are concerned, career and especially promoting had negative connotations. Currently, the negative meaning of the term has changed. Present day career is characterized by process dynamism. Statistics stress that one person changes around 3-5 jobs during ones active life. In a certain way career development supposes that the succession of one's jobs in a particular domain there existed a process of quantity increases and mainly quality ones, related to accumulating experience on the basis of professional training, abilities and competences demonstrated at one's job.

The opinion about a successful career implies the following Decalogue:

- know yourself,

- profession resides in continuous learning,

- make use of identified opportunities,

- learn from others,

- give to others,

- ask for help,

- develop yourself all the time,

- be grateful for what you have received from others or from life,

- have patience and build carefully,

- be ready for unpleasant situations as well.

Stages of career development can be seen as linked to the above mentioned: exploration, attempt, stabilizing, maintenance, middle-career crisis, job change, fulfilment or decline. Success and going through these stages is not rigid; on the contrary there is an obvious flexibility.

Generally speaking, a risk-free life can be monotonous and boring. In a career sense there is the problem: how good is it for the candidate to take risks, namely how far will he face the challenge? 
In case of a career, to remain certain on one side of the camp can be a clever and safe approach. In order, to do better than others some risks must be taken.

Most important is self-knowledge and the company where one works. Understanding what happens if you risk and things do not turn out well suppose a deep knowledge of the level of psychological strength in case of failure or of fellows' reactions. But let us have a positive approach.

Specialists suggest evaluating professional risks such as:

a) Getting involved in difficult projects. To be successful where others were not is a promoting opportunity in one's career.

b) Changing career. Every job represents a new beginning. In current social-economic conditions everyone must have a plan B ready. Risk increases significantly if the new job belongs to a different professional field. The candidate has much to learn while adaptation and performance implicitly depend on the capacity of an intellectual effort.

c) Accepting a temporary job. During one's life time potential situations impose taking decisions between accepting a temporary job, during a project, at a company less liked by the candidate. Choosing a temporary job represents a higher risk which can still bring a greater professional reward. Temporary activity can open perspective of a permanent employment at the end of the period stipulated in the contract. Nowadays the concept is frequent among young engineers, not only tough.

d) Free time between jobs. It is a risk that may bring an important personal reward. It can provide time to explore other professional options. The risk can be diminished for the career if important contacts are preserved and there are credible explanations about the usage of the time span.

e) Imposing your point of view towards the boss. The assumed risk for contradictory professional discussions is diminished if the time and place of opinion sharing is well chosen. If well-defined and convincing explanations are offered, regarding the psychological, emotional state, this could be a risk worth to be taken.

Generally speaking, if one analyses the attitude whether risks are rational or not, it must be understood that if nothing is done the situation can be risky all the same. Individual performance is strictly linked to level of psycho-social satisfaction. There are reasons for which a career can benefit from by taking risks:

a) Accumulation of experience. No matter if results are positive or negative taking risks implies future experience. There is the chance of meeting new people, of assimilating knowledge, of learning new methods.

b) Personal development takes place regardless if the result is positive or negative; it offers the chance to learn something new about oneself. One can notice changes in the thinking manner which is important for the understanding and accepting of different points of view.

c) Perfecting by assimilation. Once the young person can cumulate information, he becomes a better professional. Taking risks presupposes assimilating knowledge and abilities, well-mastered along one's career, useful in various situations. If the person does not have the courage to maintain and motivate his ideas, nobody will do it for him!

d) Choosing between good and evil. Taking a risk is not obvious if things continue according to plan. A positive attitude and the wish to get involved guarantee positive results. Career can be built gradually by taking small, modest steps. When one takes the risk to try new paths their horizon enlarges and a successful career is more possible.

\section{Conclusions}

a. Differences between the expectations of employers and those of graduates looking for a job consist in concepts linked to integration in an organization culture and personal development, loyalty towards the company, initiative and quick adaptation at the work place, maintaining one's enthusiasm in time, creative behaviour and the wish to promote together with a result orientation. 
b. The perception differences appear about aspects regarding internal structure of the company and its specific expectations: organization abilities, research, change adaptation, appreciating or not some solid knowledge in the given field.

c. The analysis of risks considered stressing by young people at work must include aspects of projection and work management as well as social and organizational aspects: not only the concrete physical ones, the psycho-social as well. As a result they affect the ability of employers and their performances. It is obvious that the health and safety of the whole company and its performance will be affected.

d. The differences between levels of expectation of the employer and of the young employees may diminish following a better knowledge of the specific of engineering companies. A solution can be early organization, even since the $2^{\text {nd }}$ academic year, attending seminaries, conferences, internships in which the expectations of the companies are presented, from future employees, better known in universities by developing more active and constant partnerships. Competitions can be created about graduation topics, about diplomas / Ph.D. papers, on projects of interest for employing companies.

Reforms are needed to replace the uniformity engineering education unit with the unit in diversity coupled with technological developments increasing trend accelerated.

\section{References}

[1] E. S. Chircu, Career start. Differences in requirements and expectations of employers and students. DTT. University Politehnica of Bucharest, Bul. Management, 2 (2012).

[2] L. Hăhăianu (ed.), Advisor - Human Resources Management, Rentrop \& Straton Publ. H., (2000).

[3] M. Jigau, Career counselling, Bucharest, Sigma Publ. H., (2001).

[4] A.G. Watts, B. Law, J. Killeen, Rethinking Careers Education and Guidance. London, Routledge Publ. H., (1996).

[5] Law no. 35/ 2006. The young people law, Of. Mon. 206 no., 6.3.2006. Publ., Romania. 